\title{
Os índios na história política do Império: avanços, resistências e tropeços
}

The Indians in the political history of the Empire: advances, resistance and stumbles

Vânia Maria Losada Moreira*

\section{Sposito, Fernanda}

Nem cidadãos, nem brasileiros: indígenas na formação do Estado nacional brasileiro e conflitos na província de São Paulo (1822-1845)

São Paulo: Alameda, 2012. 292p.

A temática indígena ainda não entrou de maneira firme na história política do Império. É essa, pelo menos, a impressão deixada por algumas obras coletivas publicadas recentemente. Ao não tratarem dos índios e das nações indígenas, essas historiografias, que se apresentam como visões panorâmicas sobre o século XIX, terminam ajudando a propagar a falsa ideia de que os índios não eram uma preocupação política dos contemporâneos, ou não representavam uma 'variável' importante para a análise da experiência histórica brasileira do período. Em Nação e cidadania no Império: novos horizontes, ${ }^{1}$ por exemplo, existem 17 capítulos e nenhum deles se dedica aos índios e às suas experiências durante o Oitocentos. O mesmo acontece em Repensando o Brasil do Oitocentos: cidadania, política e liberdade, ${ }^{2}$ com 23 capítulos, nenhum dos quais enfocando a questão indígena como eixo central da análise. Não é aceitável, contudo, continuar discutindo a formação do Estado, a consolidação do território nacional e a cidadania, durante o Império, sem considerar de maneira clara, direta e corajosa o problema dos índios, das comunidades indígenas já integradas à ordem imperial e das inúmeras nações independentes que, progressivamente, foram conquistadas ao longo do próprio século XIX. A recente publicação de $O$ Brasil Imperial, coleção em três volumes, com 33

*Departamento de História e Programa de Pós-Graduação em História, Universidade Federal Rural do Rio de Janeiro (UFRRJ). Antiga Estrada Rio-São Paulo (BR-465), km 7. 23890-000 Seropédica - RJ - Brasil.vania.vlosada@gmail.com 
capítulos, um deles dedicado aos índios, ${ }^{3}$ é digna de menção, pois representa um avanço significativo.

Uma questão importante para a compreensão política do Brasil, mas ainda muito negligenciada pela historiografia, é a posição do índio no processo político de organização do Estado nacional durante o Oitocentos. Por isso mesmo, é muito bem-vindo o livro de Fernanda Sposito Nem cidadãos, nem brasileiros: indígenas na formação do Estado nacional brasileiro e conflitos na província de São Paulo (1822-1845). ${ }^{4}$ O livro está dividido em duas partes: na primeira, intitulada "Os índios no Império: política e imaginário", a autora dedica-se a analisar o indigenismo e a política indigenista imperial, com destaque para o período entre a Independência e a emergência do Segundo Reinado.

Com sólida base empírica, a autora demonstra que, depois da Independência, a monarquia, a escravidão e a convivência com os índios tiveram de ser refundados "em novas bases, no contexto do liberalismo e do modelo constitucional moderno" (p.14). Desse ponto de vista, a questão indígena tornou-se um dos assuntos importantes da pauta política do período e foi "reenquadrada à vista de temas como cidadania, soberania nacional, mão de obra etc." (p.14). Nessa parte do texto, o objetivo central da autora é o de "perceber como os dirigentes do Estado e da nação em construção elaboraram políticas e pensamentos referentes às comunidades indígenas" (p.257). Para isso, Sposito explorou e percorreu várias searas do debate político sobre os índios, investigando a Assembleia Constituinte de 1823, o Instituto Histórico e Geográfico Brasileiro, as legislaturas do Senado, a legislação editada sobre os índios, a imprensa etc. $\mathrm{O}$ apetite da historiadora pelas fontes históricas é uma das marcas mais salientes de seu trabalho e, sem sombra de dúvidas, uma de suas maiores contribuições.

Na segunda parte, intitulada "No palco das disputas entre paulistas e indígenas", a autora traça uma história mais social do que política, realizando uma reflexão sobre a expansão das fronteiras da província de São Paulo sobre os territórios dos Kaingang, Xokleng, Guarani e Kaiowa. Explora, portanto, a história das zonas de contato e os conflitos entre 'índios' e 'paulistas'. Também aqui, a autora mobiliza um importante corpo documental sobre a província de São Paulo, fornecendo sólida base empírica à segunda parte de sua reflexão. 
A conexão que Fernanda Sposito faz entre as duas partes de seu trabalho é também digna de destaque. Isso ganha especial evidência na discussão que ela realiza sobre a abolição das cartas régias do príncipe regente d. João, que mandavam mover guerras ofensivas contra os índios de Minas Gerais, Espírito Santo e São Paulo. As cartas régias, publicadas em 1808 e 1809, foram debatidas no Senado em 1830 e revogadas pouco depois, em 1831. De forma muito apurada, Sposito demonstra, por um lado, que aquela legislação joanina ainda estava em vigor na província de São Paulo, onde os moradores se valiam dela para manter índios no cativeiro. Por outro, evidencia que a pauta política nacional movia-se, muitas vezes, em função das injunções regionais. Afinal, foi em razão da intervenção dos dirigentes paulistas que o Senado se viu na contingência de discutir a revogação das guerras e a persistência do cativeiro indígena em certas regiões do Império (p.91).

A pesquisa de Fernanda Sposito amplia o atual debate historiográfico sobre cidadania durante o Oitocentos. É importante aprofundar, por isso mesmo, a reflexão sobre algumas hipóteses e conclusões centrais sustentadas pela autora. Sobre isso, faço duas observações: a primeira diz respeito ao uso do conceito Antigo Sistema Colonial que, ao contrário de ajudar a autora na problematização das fontes, leva-a a desenvolver uma interpretação sobre a transição da política indigenista colonial para a imperial pouco satisfatória. De acordo com Sposito,

A novidade da questão indígena no Estado nacional brasileiro foi que a situação de colonização que caracteriza a relação ente os dois universos ao longo do período colonial não cabia mais no modelo de um Estado moderno. Isso foi colocado desde a época de crise do Antigo Sistema Colonial, através das políticas pombalinas para os indígenas na segunda metade do século XVIII. (p.260)

Do ponto de vista dos índios, a 'situação de colonização’ não foi superada com a emergência do Estado imperial, pois a sociedade nacional, numa espécie de colonialismo interno, continuou avançando e conquistando os territórios e as populações indígenas. A segunda parte do livro de Sposito é, aliás, um testemunho eloquente sobre isso. A diferenciação que a autora faz entre as políticas indigenistas colonial e nacional não se baseia na análise dos fatos. É antes caudatária de uma avaliação limitada sobre a política portuguesa em relação aos índios, entendida fundamentalmente como uma "política ofensiva 
de extermínio e escravização" (p.36), temporariamente suspensa durante o regime do Diretório dos Índios, quando prevaleceu a política de incorporação deles na qualidade de vassalos da monarquia portuguesa (p.37). Nem a documentação primária, citada pela própria autora, nem a historiografia mais recente sobre a política indigenista colonial corroboram sua interpretação. ${ }^{5}$ Afinal, se uma das faces da política indigenista colonial foi, de fato, a guerra, o extermínio e o cativeiro, a outra foi a territorialização ${ }^{6}$ dos índios por meio dos aldeamentos, transformando-os em súditos e vassalos da Coroa, com uma série de direitos e obrigações. ${ }^{7}$ Mais ainda, os aldeamentos - nos moldes preconizados por Manoel da Nóbrega e, posteriormente, regulamentados pelo Regimento das Missões de 1686 - e o Diretório pombalino foram as duas experiências coloniais nas quais os políticos e os intelectuais do Império se basearam para pensar e propor uma nova política de Estado para a incorporação dos índios à ordem imperial. ${ }^{8}$

A segunda e última observação diz respeito a uma das teses centrais do livro, ou seja, a de que o pacto político selado depois da Independência excluiu os índios da sociedade civil e política, porque eles não foram mencionados no texto constitucional (p.78). Assim, entre a Independência e a promulgação do Regulamento de Catequese e Civilização dos Índios, em 1845, “os indígenas não eram reconhecidos como cidadãos e tampouco como brasileiros" (p.258). Ainda segundo a autora, essa exclusão serve para explicar acontecimentos importantes, como a continuidade de 'práticas coloniais' no Império, como as guerras e as escravizações.

A ausência de uma definição precisa sobre o estatuto jurídico dos índios ou de um capítulo específico sobre a 'civilização dos índios bravos' na Constituição de 1824, tal como queria José Bonifácio e vários constituintes da Assembleia de 1823, não são condições suficientes, contudo, para postular a exclusão dos índios do pacto político imperial. Afinal, a situação jurídica dos índios pode ter ficado incerta e sob disputa, mas isso não significa que eles ficaram de fora do pacto político do período. Além disso, a própria autora demonstra que a demora em se criar uma legislação global sobre como lidar com os índios 'bravos' não se deveu à falta de interesse político pela questão, já que existiam diferentes projetos e propostas, mas sim à falta de consenso sobre o assunto (p.259). 
Os constituintes de 1823 insistiram no argumento de que existiam no território do Império dois tipos diversos de índios, os 'bravos' e os 'domesticados', e cada um deles exigia um enfoque político diferente. Em relação aos 'bravos', sugeriu-se que eles precisavam ser, primeiro, 'civilizados' e integrados à sociedade para, depois, gozarem dos direitos políticos de cidadãos. Quanto aos índios 'domesticados', não se disse muito sobre eles na Constituinte. Mas o pouco discutido desenvolveu-se no sentido de considerá-los homens livres e nascidos no território brasileiro, por isso mesmo plenamente capazes de gozarem do título de cidadãos brasileiros. A política indigenista do Primeiro Reinado tampouco autoriza a afirmação de que os índios ficaram de fora do pacto político do período pós-Independência. Apesar de ter permitido bandeiras contra grupos indígenas considerados agressores, também mandou formar aldeamentos para outros considerados 'selvagens', mas não inimigos, e tratou como cidadãos certos grupos aldeados e avaliados como suficientemente 'civilizados', mandando regê-los segundo as leis ordinárias do Império. Os próprios índios, além disso, apropriaram-se da alcunha de 'cidadãos brasileiros' para lutarem por seus interesses, sem que isso soasse como uma reivindicação inapropriada ou extemporânea (Moreira, 2010).

Concluo estas considerações lembrando o que disse o índio Marawê, do Parque Nacional do Xingu. Para ele, a história dos índios se divide em a.B. e d.B., isto é, em "antes e depois do branco". ${ }^{9} \mathrm{Na}$ longa história indígena d.B., a transição da Colônia para o Império não representou uma ruptura profunda, mas trouxe algumas mudanças significativas que precisam ser, de fato, salientadas. A mais significativa foi, do meu ponto de vista, o crescente desuso de uma perspectiva de cidadania típica do antigo regime, quando ser índio e parte do corpo político e social, na qualidade de vassalo, era situação perfeitamente aceitável e ajustável. ${ }^{10}$ Em outras palavras, com o aprofundamento do liberalismo e do nacionalismo na ordem social e política do Império, aprofundou-se, também, a política de 'assimilação', entendida e praticada com o objetivo de dissolver o índio na sociedade nacional. Desse ângulo, Fernanda Sposito está bastante certa ao afirmar que a expectativa política dominante no período era a de considerar o índio "brasileiro ou, hipoteticamente cidadão, se deixasse, justamente de ser indígena” (p.143). Durante o Império, portanto, um dos desafios da política indígena foi lidar com os processos de cidadanização e nacionalização da política indigenista, que foram especialmente vorazes depois 
da promulgação da Lei de Terras de 1850, quando se intensificou a liquidação de aldeias e a desamortização das terras indígenas.

\section{NOTAS}

${ }^{1}$ CARVALHO, José Murilo de. Nação e cidadania no Império: novos horizontes. Rio de Janeiro: Civilização Brasileira, 2007.

${ }^{2}$ CARVAlHO, José Murilo de; NEVES, Lúcia Maria B. P. (Org.). Repensando o Brasil do Oitocentos: cidadania, política e liberdade. Rio de Janeiro: Civilização Brasileira, 2009.

${ }^{3}$ SAMPAIO, Patrícia Melo. Política indigenista no Brasil imperial. In: GRINBERG, Keila; SALLES, Ricardo (Org.). O Brasil Imperial - 1808-1831. Rio de Janeiro: Civilização Brasileira, 2009. p.175-206.

${ }^{4}$ SPOSITO, Fernanda. Nem cidadãos, nem brasileiros: indígenas na formação do Estado nacional brasileiro e conflitos na província de São Paulo (1822-1845). São Paulo: Alameda, 2012.

${ }^{5}$ PERRONE-MOISÉS, Beatriz. Índios livres e índios escravos: os princípios da legislação indigenista no período colonial (séculos XVI a XVIII). In: CUNHA, Manuela Carneiro da (Org.). História dos índios no Brasil. São Paulo: Companhia das Letras; Secretaria Municipal de Cultura; Fapesp, 1992. p.115-132.

' OLIVEIRA, João Pacheco de. Uma etnologia dos “índios misturados"? Situação colonial, territorialização e fluxos culturais. Mana, v.4, n.1, p.47-77, 1998.

${ }^{7}$ ALMEIDA, Maria Regina Celestino de. Metamorfoses indígenas: identidade e cultura nas aldeias coloniais do Rio de Janeiro. Rio de Janeiro: Arquivo Nacional, 2003.

${ }^{8}$ MOREIRA, Vânia Maria Losada. De índio a guarda nacional: cidadania e direitos indígenas no Império (vila de Itaguaí, 1822-1836). Topoi, Rio de Janeiro, v.11, n.21, p.127-142.

${ }^{9}$ CUNHA, Manuela Carneiro da. Cultura com aspas e outros ensaios. São Paulo: Cosac Naify, 2009. p.129.

${ }^{10}$ MOREIRA, Vânia Maria Losada. O ofício do historiador e os índios: sobre uma querela no Império. Revista Brasileira de História, São Paulo, v.30, n.59, 2010, p.53-72.

Resenha recebida em 25 de setembro de 2012. Aprovada em 17 de outubro de 2012. 